\title{
Financing Buprenorphine Treatment in Primary Care: A Microsimulation Model
}

\author{
Jonathan E. Fried ${ }^{*}$ \\ Sanjay Basu, $M D, P b D^{1,2,3^{*}}$ \\ Russell S. Pbillips, $M D^{1,4}$ \\ Bruce E. Landon, $M D, M B A^{1,4,5}$ \\ *These authors contributed equally \\ as co-first authors.
}

${ }^{1}$ Center for Primary Care, Harvard Medical School, Boston, Massachusetts

${ }^{2}$ Research and Population Health, Collective Health, San Francisco, California

${ }^{3}$ School of Public Health, Imperial College London, London, United Kingdom

${ }^{4}$ Division of General Internal Medicine and Primary Care, Beth Israel Deaconess Medical Center, Boston, Massachusetts

${ }^{5}$ Department of Health Care Policy, Harvard Medical School, Boston,

Massachusetts

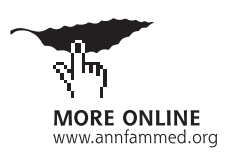

Conflicts of interest: R.S.P. is an adviser to Bicycle Health, an early startup that is working on a product to assist primary care physicians in caring for patients with chronic pain. B.E.L. is a consultant to RTI, Inc and UpToDate, Inc. The remaining authors report none.

\section{CORRESPONDING AUTHOR}

Sanjay Basu, MD, PhD

Center for Primary Care,

Harvard Medical School

635 Huntington Ave

Boston, MA 02115

sanjay_basu@hms.harvard.edu

\begin{abstract}
PURPOSE We sought to determine the financial impact to primary care practices of alternative strategies for offering buprenorphine-based treatment for opioid use disorder.

METHODS We interviewed 20 practice managers and identified 4 approaches to delivering buprenorphine-based treatment via primary care practice that differed in physician and nurse responsibilities. We used a microsimulation model to estimate how practice variations in patient type, payer, revenue, and cost across primary care practices nationwide would affect cost and revenue implications for each approach for the following types of practices: federally qualified health centers (FQHCs), non-FQHCs in urban high-poverty areas, non-FQHCs in rural highpoverty areas, and practices outside of high-poverty areas.
\end{abstract}

RESULTS The 4 approaches to buprenorphine-based treatment included physician-led visits with nurse-led logistical support; nurse-led visits with physician oversight; shared visits; and solo prescribing by physician alone. Net practice revenues would be expected to increase after introduction of any of the 4 approaches by $\$ 18,000$ to $\$ 70,000$ per full-time physician in the first year across practice type. Yet physician-led visits and shared medical appointments, both of which relied on nurse care managers, consistently produced the greatest net revenues $(\$ 29,000-\$ 70,000$ per physician in the first year). To ensure positive net revenues with any approach, providers would need to maintain at least 9 patients in treatment, with a no-show rate of $<34 \%$.

CONCLUSIONS Using a simulation model, we estimate that many types of primary care practices could financially sustain buprenorphine-based treatment if demand and no-show rate requirements are met, but a nurse care managerbased approach might be the most sustainable.

Ann Fam Med 2020;18:535-544. https://doi.org/10.1370/afm.2587.

\section{INTRODUCTION}

$\mathrm{O}$ ffice-based treatment with buprenorphine is a safe and effective medication-assisted treatment approach for opioid use disorder. ${ }^{1-6}$ Buprenorphine offers the opportunity for primary care providers to treat opioid use disorder with a safer alternative to methadone; buprenorphine is a partial opioid receptor agonist-antagonist that confers lower risk of respiratory depression, and it is typically coformulated with naloxone to reduce the risk of abuse via injection. ${ }^{7-11}$ To prescribe buprenorphine, US physicians must undergo 8 hours of training to obtain a prescription waiver, which initially limits physicians to treating at most 30 patients at a time (this limit can be increased over time).

Buprenorphine therapy has been limited in high-need areas, ${ }^{12-16}$ potentially owing to the waiver training requirement but also to uncertainty regarding how instituting a buprenorphine treatment program might affect practice finances. ${ }^{17-24}$ Whereas buprenorphine treatment is cost effective in terms of improving quality-adjusted life-years in the population relative to the cost of the drug, whether it is financially beneficial to practices to invest in the training, infrastructure, workforce, and time to 
deliver buprenorphine remains uncertain. ${ }^{25-27}$ The aim of the present study was to estimate the financial effect of buprenorphine-based treatment on primary care practices using alternative delivery approaches.

\section{METHODS}

Our methodologic approach followed the Consolidated Health Economic Evaluation Reporting Standards (Supplemental Table 1, https://www.AnnFam Med.org/content/18/6/535/supp1/DC1/). ${ }^{28}$

\section{Identification and Process Mapping of Buprenorphine Treatment Approaches}

We first identified buprenorphine-based treatment approaches in primary care settings via review of the published and gray literature. ${ }^{29,30}$ We limited our analysis to office-based opioid treatment with buprenorphine models that could be delivered with limited institutional support, omitting hub-and-spoke approaches that required a centralized induction facility or were limited to populations with specific comorbidities (eg, pregnant women, people with HIV). ${ }^{29}$ Because buprenorphine therapy can be provided by nonphysicians, we included models with nonphysician prescribers as well as those with physician prescribers.

We assessed delivery approaches using a semistructured qualitative telephone interview (Supplemental Appendix, https://www.AnnFamMed. org/content/18/6/535/suppl/DC1/) with primary care practice leaders engaged in buprenorphine prescribing in the United States. The semistructured interview guide featured the following 6 domains: (1) practice and patient demographics, (2) practice workflows, (3) patient outcomes, (4) business model including documentation and billing, (5) startup and operating costs,

(6) startup process and challenges. The guide was adjusted after pilot testing with the first 3 respondents. Interviews were conducted by J.E.F., lasted approximately 1 hour, and were transcribed. We analyzed transcripts using the principles of grounded theory. ${ }^{31,32}$ Our thematic analysis proceeded in the following 3 stages: independent identification of themes by 2 investigators, refinement of themes to generalized models after comparison with literature-identified practice models, and validation of refined practice models with initial interview transcripts.
We identified potential interview candidates by consulting our professional networks, contacting authors of articles identified in the literature review, and publishing a Twitter-based solicitation and then used snowball sampling to identify further respondents. After preliminary thematic analysis to categorize care delivery models, interviews were halted after 20 responses, at which point we reached saturation on the final 4 approaches (Figure 1). Of the 20 respondents, 5 practiced in federally qualified health centers (FQHCs), 5 in non-FQHCs in urban high-poverty ZIP Codes, 2 in non-FQHCs in rural high-poverty ZIP Codes, and 8 in non-FQHCs in low-poverty ZIP Codes. Fifteen practiced in New England, 2 in mid-Atlantic and Midwestern states, respectively, and 1 on the West Coast.

Based on the interviews, we developed a process map for each approach (Supplemental Appendix, https://www.AnnFamMed.org/content/18/6/535/suppl/ DC1/) to estimate personnel, infrastructure, and demand for each approach in both the initial year of offering buprenorphine and in subsequent years. The data from the qualitative interviews were then used to create the simulation model as detailed below.

\section{Defining Target Population and Subgroups}

The interview data were used to build a microsimulation model to estimate costs and revenues in different practice settings. ${ }^{33}$ The model incorporated data from
Figure 1. Description of identified buprenorphine care delivery models.

OBOT with physician-led visits
NCMs support waivered buprenorphine prescribers.
Regular visits are prescriber led and billed. NCMs provide
logistical (program coordination) and clinical (intake visit,
telephone outreach, induction management) support and
serve as the patient's first point of contact. Prescribers
primarily focus on medication management.
OBOT with nurse-led visits
$\begin{aligned} & \text { NCMs lead and bill patient visits and provider care man- } \\ & \text { agement under the direction of a waivered buprenor- } \\ & \text { phine prescriber. Patients meet with the prescriber every } \\ & \text { 3 months for medication management. } \\ & \text { OBOT with shared visits } \\ & \text { Prescribers lead weekly group visits with mental health } \\ & \text { professional and NCM, at which patients receive addiction- } \\ & \text { focused medical evaluation and management, buprenor- } \\ & \text { phine prescription, and group psychotherapy. Before start- } \\ & \text { ing group psychotherapy, the patient has individual visits } \\ & \text { with the provider, NCM, and mental health professional } \\ & \text { and receives a bridging prescription. } \\ & \text { Solo prescriber } \\ & \text { The prescriber independently manages opioid use disorder } \\ & \text { without major structural support from other disciplines. }\end{aligned}$


our interviews of selected practices and from national practice data sets (sources listed in Tables 1-3) and then simulated costs as well as gross and net revenues per full-time physician for each of the following 4 practice subgroups: (1) FQHCs and FQHC look-alikes, (2) non-FQHC practices in high-poverty urban areas by Census definition $(\geq 20 \%$ of households within the ZIP Code having an income below the federal poverty threshold after adjustment for household size), (3) nonFQHC practices in high-poverty rural areas by Census definition $(\geq 20 \%$ of households within the ZIP Code having an income below the federal poverty threshold after adjustment for household size), and (4) practices outside of high-poverty areas.

\section{Modeling Practice Costs and Revenues}

The model simulated 10,000 representative individual practices for each of the 4 practice subgroups. In the model, each practice was simulated by sampling from the data sources specified in Tables 1-3. The data sources provided estimates for how many patients would be expected to qualify for buprenorphine at each type of practice, how many visits each of those patients would typically attend and with what kind of provider (physician, nurse, or behaviorist [social worker or clinical psychologist]), how much time and expense would be associated with providing these visits (including personnel costs, overhead, and opportunity costs of forgoing routine medical visits for time required with the physician), and how much revenue would be expected from each type of buprenorphine visit. As shown in Tables 1-3, we specifically accounted for the distribution of Medicare, Medicaid, privately insured, and uninsured/self-paying patients at each type of clinic; patient volume (up to the 30-patient-per-provider limit that currently applies to $74 \%$ of waivered physicians who have not successfully applied to increase their patient limit), ${ }^{45}$ false-positive screens, no-show rates, and attrition over time; and different payment rates by payer, provider type, and visit type. As was typical

Table 1. Input Data and Descriptive Details for Alternative Approaches for Office-Based Opioid Treatment With Buprenorphine

\begin{tabular}{|c|c|c|c|c|}
\hline & $\begin{array}{c}\text { OBOT-B With } \\
\text { Physician-Led Visits }{ }^{4}\end{array}$ & $\begin{array}{c}\text { OBOT-B With } \\
\text { Nurse-Led Visits }{ }^{34}\end{array}$ & $\begin{array}{l}\text { OBOT-B With } \\
\text { Shared Visits }\end{array}$ & $\begin{array}{l}\text { OBOT-B With } \\
\text { Solo Provider }\end{array}$ \\
\hline \multicolumn{5}{|l|}{$\begin{array}{l}\text { Visit frequency (per patient per year), } \\
\text { based on interviews, No. }\end{array}$} \\
\hline Initial medical evaluation (99204/G0466ª) & 1 & 1 & 1 & 1 \\
\hline $\begin{array}{l}\text { Follow-up medical evaluation, Level } 3 \\
\text { (99213/G0467) }\end{array}$ & 15 & 1 & 18 & 16 \\
\hline $\begin{array}{l}\text { Follow-up medical evaluation, Level } 4 \\
\text { (99214/G0467) }\end{array}$ & 1 & 4 & 0 & 1 \\
\hline Follow-up nursing visit (99211) & 0 & 13 & 1 & 0 \\
\hline $\begin{array}{l}\text { Behavioral health intake assessment } \\
\text { (90791/G0469; combined with initial } \\
\text { medical evaluation) }\end{array}$ & 1 & 1 & 1 & 0 \\
\hline $\begin{array}{l}\text { Group psychotherapy (90853), } 12 \text { patients } \\
\text { per group }\end{array}$ & 19 & 19 & 18 & 0 \\
\hline Urine drug screen (80305/G0477) & 19 & 19 & 20 & 18 \\
\hline \multicolumn{5}{|l|}{ Staff time, based on interviews } \\
\hline Physician hours (SD), per patient per year & $4.8(1.2)$ & $2.0(0.5)$ & $2.9(0.7)$ & $5.2(1.3)$ \\
\hline $\begin{array}{l}\text { Nurse care manager hours (SD), per } \\
\text { patient per year }\end{array}$ & $1.1(0.3)$ & $4.0(1.0)$ & $4.0(1.0)$ & $\cdots$ \\
\hline Behaviorist hours (SD), per patient per year & $2.4(0.7)$ & $2.5(0.8)$ & $3.0(0.8)$ & $\ldots$ \\
\hline Year 1 additional physician hours (SD) & $16.0(5.0)$ & $16.0(5.0)$ & $16.0(5.0)$ & $32.0(10.0)$ \\
\hline $\begin{array}{l}\text { Year } 1 \text { nurse and behaviorist additional } \\
\text { setup hours (SD) }\end{array}$ & $40.0(10.0)$ & $40.0(10.0)$ & $40.0(10.0)$ & $\cdots$ \\
\hline $\begin{array}{l}\text { Hours (SD) worked per full-time equivalent } \\
\text { employee per year }{ }^{37}\end{array}$ & $2,087.0(96.0)$ & $2,087.0(96.0)$ & $2,087.0(96.0)$ & $2,087.0(96.0)$ \\
\hline \multicolumn{5}{|c|}{ OBOT-B = office-based opioid treatment with buprenorphine. } \\
\hline \multicolumn{5}{|c|}{$\begin{array}{l}\text { Note: For insurance rates, we sampled from the probability distribution of Medicare payer prevalence. If a simulated individual was not selected to have Medicare, } \\
\text { we sampled from the Medicaid prevalence. If the simulated individual was not selected to have Medicaid, we sampled from the private insurance prevalence. If the } \\
\text { individual was not selected to have private insurance, they were assigned as self-pay/uninsured. Payment rates were log-transformed before sampling to adjust for skew } \\
\text { and were determined from the Medicare Physician Fee Schedule Look-up Tool, publicly available state Medicaid fee schedules, and the Collective Health database } \\
\text { of commercial payment rates. }{ }^{42-44} \text { Appropriate billing codes for OBOT-B were determined in consultation with interviewed primary care practice representatives and } \\
\text { informed by guidance from the Centers for Medicare } \& \text { Medicaid Services, Substance Abuse and Mental Health Services Administration, and National Association of } \\
\text { Community Health Centers. }{ }^{36-38}\end{array}$} \\
\hline Current Procedural Terminology (CPT) visit codes. & & & & \\
\hline
\end{tabular}


among interviewed practices, we assumed uninsured/ self-paying patients would be charged rates equivalent to Medicaid (the lowest rates among insured payers).

\section{Incorporating Buprenorphine Into Practice Costs and Revenues}

New personnel and overhead costs associated with offering buprenorphine, as well as opportunity costs attributable to startup costs in the first year of implementation, were estimated from practice interviews, survey data from the Medical Group Management Association, ${ }^{40}$ and the US Bureau of Labor Statistics. ${ }^{41}$ New personnel and overhead costs included wages for newly hired or repurposed staff and purchasing dedicated clinic space and drug screening kits. Startupassociated costs included the time required to obtain a waiver, conduct training, and establish new workflows.

To estimate the remaining proportion of costs attributable to billable time repurposed to treatment and care coordination for patients receiving buprenorphine for opioid use disorder, we estimated the number of additional patients that would be treated for each practice type, the number of existing physician visits displaced by buprenorphine treatment time (opportunity costs), and the staff resources necessary to deliver this care. We estimated the prevalence of untreated opioid use disorder for each practice type by cross-walking estimates of opioid dependence or abuse in the past year from the National Survey on Drug Use and Health $(2017 ; \mathrm{n}=68,032),{ }^{38}$ stratified by health insurance type, to estimates of payer mix for each type of practice from Medical Group Management Association's DataDive, ${ }^{40}$ taking into account the proportion of patients with opioid use disorder who do not currently receive treatment. As shown in Table 2, baseline opioid use disorder prevalence estimates varied from $0.8 \%$ to $1.6 \%$ across practice types. We simulated that these patients would be identified via universal single-question screening for drug use disorder and varied the proportion of these patients who would accept treatment, show up to visits, and be retained over time.

\section{Computation of Outcome Variables}

Outcome variables were computed from the practice manager perspective. The primary outcome was

Table 2. Input Data and Descriptive Details for Practice-Level Data by Clinic Type

\begin{tabular}{|c|c|c|c|c|}
\hline & $\begin{array}{l}\text { FQHC or FQHC } \\
\text { Look-Alike }\end{array}$ & $\begin{array}{l}\text { Non-FQHC in High- } \\
\text { Poverty Urban ZIP } \\
\text { Code ( } \geq 20 \% \text { of } \\
\text { Households Below } \\
\text { Poverty Threshold) }\end{array}$ & $\begin{array}{l}\text { Non-FQHC in High- } \\
\text { Poverty Rural ZIP } \\
\text { Code ( } \geq 20 \% \text { of } \\
\text { Households Below } \\
\text { Poverty Threshold) }\end{array}$ & $\begin{array}{l}\text { Practice } \\
\text { in Lower- } \\
\text { Poverty } \\
\text { ZIP Code }\end{array}$ \\
\hline \multicolumn{5}{|l|}{ Demand for therapy } \\
\hline Prevalence of opioid use disorder, \% (SD) ${ }^{38}$ & $1.3(0.2)$ & $1.3(0.2)$ & $1.6(0.4)$ & $0.8(0.3)$ \\
\hline Screening tool sensitivity, \% (SD) ${ }^{39}$ & $100.0(0)$ & $100.0(0)$ & $100.0(0)$ & $100.0(0)$ \\
\hline Screening tool specificity, \% (SD) ${ }^{39}$ & $73.5(1.8)$ & $73.5(1.8)$ & $73.5(1.8)$ & $73.5(1.8)$ \\
\hline $\begin{array}{l}\text { Proportion of patients accepting therapy when } \\
\text { offered, based on interviews, \% (SD) }\end{array}$ & $80.0(2.5)$ & $80.0(2.5)$ & $80.0(2.5)$ & $80.0(2.5)$ \\
\hline No-show rate, $\%(S D)^{26}$ & $22.0(5.0)$ & $20.0(5.0)$ & $25.0(5.0)$ & $20.0(5.0)$ \\
\hline \multicolumn{5}{|l|}{ Practice characteristic } \\
\hline $\begin{array}{l}\text { Panel size, all patients per full-time physician, } \\
\text { No. (SD) }\end{array}$ & $2,040(551)$ & $1,480(316)$ & $1,760(357)$ & $1,620(337)$ \\
\hline Payer prevalence, Medicare, $\%(S D)^{40}$ & $11(3)$ & $27(7)$ & $20(5)$ & $22(6)$ \\
\hline Payer prevalence, Medicaid, \% (SD) ${ }^{40}$ & $57(14)$ & $20(5)$ & $18(5)$ & $13(3)$ \\
\hline Payer prevalence, private, \% (SD) ${ }^{40}$ & $10(3)$ & $48(12)$ & $48(12)$ & $60(15)$ \\
\hline Payer prevalence, uninsured/self-pay, \% (SD) ${ }^{40}$ & $22(6)$ & $5(1)$ & $14(4)$ & $5(1)$ \\
\hline \multicolumn{5}{|l|}{ Salary and overhead costs ${ }^{26,40,41}$} \\
\hline Nurse care manager salary per year, \$ (SD) & $65,683(8,624)$ & $73,101(7,418)$ & $57,059(8,624)$ & $81,724(8,623)$ \\
\hline Behaviorist salary per year, $\$(S D)$ & $50,713(9,321)$ & $58,266(7,553)$ & $41,392(9,321)$ & $67,957(9,691)$ \\
\hline Overhead rate, \% (SD) & $47(14)$ & $47(14)$ & $47(14)$ & $47(14)$ \\
\hline \multicolumn{5}{|c|}{$\mathrm{FQHC}=$ federally qualified health center; OBOT-B = office-based opioid treatment with buprenorphine. } \\
\hline \multicolumn{5}{|c|}{$\begin{array}{l}\text { Note: For insurance rates, we sampled from the probability distribution of Medicare payer prevalence. If a simulated individual was not selected to have Medicare, } \\
\text { we sampled from the Medicaid prevalence. If the simulated individual was not selected to have Medicaid, we sampled from the private insurance prevalence. If the } \\
\text { individual was not selected to have private insurance, they were assigned as self-pay/uninsured. Payment rates were log-transformed before sampling to adjust for skew } \\
\text { and were determined from the Medicare Physician Fee Schedule Look-up Tool, publicly available state Medicaid fee schedules, and the Collective Health database } \\
\text { of commercial payment rates. }{ }^{42-44} \text { Appropriate billing codes for OBOT-B were determined in consultation with interviewed primary care practice representatives and } \\
\text { informed by guidance from the Centers for Medicare } \& \text { Medicaid Services, Substance Abuse and Mental Health Services Administration, and National Association of } \\
\text { Community Health Centers. }{ }^{36-38}\end{array}$} \\
\hline
\end{tabular}


Table 3. Input Data and Descriptive Details for Payment by Insurance Type ${ }^{42-44}$

\begin{tabular}{|c|c|c|c|c|}
\hline Visit Type & $\begin{array}{c}\text { Medicare } \\
\$(S D)\end{array}$ & $\begin{array}{l}\text { Medicaid } \\
\$(S D)\end{array}$ & $\begin{array}{l}\text { Private } \\
\$(S D)\end{array}$ & $\begin{array}{c}\text { Uninsured } I \\
\text { Self-Pay \$ (SD) }\end{array}$ \\
\hline Initial medical evaluation (99204/G0466ª) & $158.80(22.80)$ & $106.60(31.40)$ & $222.70(2.40)$ & $106.60(31.40)$ \\
\hline Follow-up medical evaluation, Level 3 (99213/G0467) & $68.00(13.80)$ & $45.50(12.70)$ & $111.10(0.90)$ & $45.50(12.70)$ \\
\hline Follow-up medical evaluation, Level 4 (99214/G0467) & $101.70(18.20)$ & $68.60(21.20)$ & $156.70(1.20)$ & $68.60(21.20)$ \\
\hline Follow-up nursing visit (99211) & $17.40(7.60)$ & $10.80(6.20)$ & $46.80(1.80)$ & $10.80(6.20)$ \\
\hline Behavioral health intake assessment (90791/G0469) & $142.60(11.70)$ & $73.10(6.00)$ & $126.40(2.70)$ & $73.10(6.00)$ \\
\hline Group psychotherapy (90853), 12 patients per group & $28.00(2.20)$ & $14.40(1.10)$ & $151.90(21.30)$ & $14.40(1.10)$ \\
\hline Urine drug screen (80305/G0477) & $13.50(2.80)$ & $11.90(2.50)$ & $55.00(27.30)$ & $11.90(2.50)$ \\
\hline \multicolumn{5}{|l|}{ OBOT-B = office-based opioid treatment with buprenorphine. } \\
\hline \multicolumn{5}{|c|}{$\begin{array}{l}\text { Note: For insurance rates, we sampled from the probability distribution of Medicare payer prevalence. If a simulated individual was not selected to have Medicare, } \\
\text { we sampled from the Medicaid prevalence. If the simulated individual was not selected to have Medicaid, we sampled from the private insurance prevalence. If the } \\
\text { individual was not selected to have private insurance, they were assigned as self-pay/uninsured. Payment rates were log-transformed before sampling to adjust for sken } \\
\text { and were determined from the Medicare Physician Fee Schedule Look-up Tool, publicly available state Medicaid fee schedules, and the Collective Health database } \\
\text { of commercial payment rates. } \text {. }^{42-44} \text { Appropriate billing codes for OBOT-B were determined in consultation with interviewed primary care practice representatives and } \\
\text { informed by guidance from the Centers for Medicare \& Medicaid Services, Substance Abuse and Mental Health Services Administration, and National Association of } \\
\text { Community Health Centers. }{ }^{36-38}\end{array}$} \\
\hline \multicolumn{5}{|l|}{${ }^{a}$ Current Procedural Terminology (CPT) visit codes. } \\
\hline
\end{tabular}

change in net revenue per full-time physician per year after buprenorphine implementation vs before buprenorphine implementation. Secondary outcomes included (1) opportunity costs defined as revenue losses owing to lost payments for routine medical visits sacrificed to free the physician for any visits requiring physician presence for induction and/or titration of buprenorphine, (2) total new costs defined as opportunity costs plus the additional personnel and overhead costs of buprenorphine treatment, and (3) total new revenue from buprenorphine based on payments for each buprenorphine visit.

Outcomes were computed for the first year of implementation (including costs for setup, infrastructure, and workforce) and for each subsequent year on an annual basis for 10 years in undiscounted 2019 US dollars. All practices were simulated to implement new workflows during the first year, corresponding to the information received during our practice interviews.

\section{Sensitivity Analyses}

We varied the 2 parameters that we observed to be least precisely estimated a priori and most subject to variation among the practices we interviewed to identify the degree to which these key variables affected net revenue. These were no-show rate for induction and maintenance visits and the prevalence of opioid use disorder (proportional to demand for services/ patients accepting treatment) across broad ranges. The no-show rate was varied from $15 \%$ to $85 \%$ (from the baseline of $20 \%$ to $25 \%$ across practice types). In addition, the prevalence of opioid use disorder was varied from $0.1 \%$ to $3 \%$ (from the baseline of $0.8 \%$ to $1.6 \%$ across practice types).

\section{Uncertainty Analyses}

We sampled 10,000 times with replacement from normal probability distributions constructed from the means and SDs in Tables 1-3 to estimate the uncertainty of each model outcome, with percentage values capped at 0 or 1 . The model was programmed in $\mathrm{R}(\mathrm{v}$. 3.6.1; R Foundation for Statistical Computing) using the code posted in an open-source online repository for transparency and reproducibility (https://www. github.com/sanjaybasu/OBOT).

\section{RESULTS}

We present our results by buprenorphine delivery approach and by each of the 4 clinic subgroups for the first year of implementation (accounting for setup costs) and for each subsequent year.

\section{Delivery Approaches}

We identified 4 approaches for prescribing buprenorphine for patients with opioid use disorder in the primary care setting (Figure 1). These were (1) therapy via prescriber-led visits, which involved prescribers leading routine visits for medication management, with a nurse care manager providing program coordination, intake visits, telephone outreach, and induction management $_{i}(2)$ therapy via nurse-led visits, which involved a nurse care manager leading patient visits and care management and prescribers meeting the patient every 3 months after induction for medication management ${ }_{i}$ (3) therapy via shared medical appointments, which involved prescribers leading a weekly group visit (including medication titration) in concert with a behaviorist and nurse care manager ${ }_{i}$ and (4) 
therapy via a solo prescriber, which involved the physician prescribing buprenorphine without major structural support from auxiliary staff. The details of the 4 approaches, including care coordination, initial outreach, induction management, non-face-to-face patient care time, numbers and types of visits by provider, and cost and payment levels, are detailed in Tables 1-3, which show our estimates of demand and retention across clinic types and delivery approaches.

\section{Year 1 Implementation Results}

In Year 1 of implementation, all 4 approaches for prescribing buprenorphine generated positive net revenue for simulated primary care practices, irrespective of practice type (net revenue range $\$ 18,000$ - $\$ 70,000$ per full-time physician across practice types) (Table 4 ). Whereas net revenues varied based on the prevalence of opioid use disorder in the practice, the degree of variation was mitigated by the per-provider cap of 30 patients taking buprenorphine at any one time. The 2 approaches generating the most net revenue across practice type were shared medical appointments and physician-led visits (both producing net revenue ranges from $\$ 29,000$ to $\$ 70,000$ per full-time physician per year across practice types). In contrast, the solo prescriber approach, given the limited number of visits possible for a solo provider to fit into a year, consistently generated the lowest net revenue of the 4 approaches ( $\$ 18,000$ to $\$ 38,000$ across practice types). In the solo prescribing approach, physician time was used for all aspects of buprenorphine prescribing and follow-up (average solo provider physician hours per patient per year $=5.2$, vs 4.8 with physician-led visits, 2.0 with nurse-led visits, and 2.9 with shared visits) (Table 1 ). The employment of nurse care managers produced greater personnel costs for approaches that relied more heavily on them, namely nurse-led visits and shared medical appointments (costing $\$ 8,000$ to $\$ 10,000$ across practice types per full-time physician per year) (Table 4). Whereas payment rates for nurse-led visits were also less than that for provider-led visits, the nurse-led models added revenues in the form of group psychotherapy, which more than made up for the lost revenues from the physician-nurse visit payment difference.

Among different practice types, net revenues were consistently greatest for rural practices (ranging from $\$ 38,000$ to $\$ 70,000$ across delivery approaches), owing to the lower personnel costs in these settings and the greater prevalence of opioid use disorder, generating a high volume of demand. In contrast, the least net revenues were observed in FQHCs and look-alikes (ranging from $\$ 22,000$ to $\$ 29,000$ across approaches) because the higher wages in predominantly urban FQHC settings and the lower rates of payment from Medicaid combined to produce smaller margins despite FQHC add-on code revenue.

\section{Subsequent Year Implementation Results}

In each subsequent year of implementation, net revenues were positive for all prescribing approaches and practice types (Table 4). However, incremental relative net revenue gain from Year 1 to subsequent years ranged from $4.7 \%$ (physician-led approach in rural practices) to $18.7 \%$ (nurse-led approach in higherincome-area practices). For most practice types, practices using nurse-led visits experienced the greatest gain in net revenue, whereas those using solo prescribers had the least gain in net revenue.

\section{Sensitivity Analyses}

Figures 2 and 3 show the minimum amount of net revenue when the no-show rate and the prevalence of opioid use disorder were varied in the model. Net revenue decreased with greater no-show rates, such that no-show rates needed to be maintained at $<34 \%$ during and after induction to ensure that net revenues across all practice types were always positive regardless of implementation approach (Figure 2). As shown in Figure 3, the net revenues from buprenorphine treatment were nonlinearly scaled with the prevalence of opioid use disorder (which is proportional to demand) because if the demand for services fell below the typical 30-person limit per provider, the opportunity costs and staffing costs were similar to higher-demand situations, but the actual revenue was less, producing a disproportionate loss of revenue relative to cost. Similarly, minimum net revenues capped at a certain level $(2.8 \%$ prevalence), beyond which new net revenues were not achievable, owing to the 30-patient cap. Practices would need to maintain at least 9 patients per provider at any given time, according to our model, for all of the implementation approaches to maintain a positive net revenue across all practice types. Equivalently, at least $40 \%$ of patients screening positive for opioid use disorder would typically need to accept therapy for all simulated practices to maintain net positive revenue.

\section{DISCUSSION}

We used a simulation model to identify the financial implications for primary care practices of adopting any of 4 common approaches to buprenorphine-based treatment of opioid use disorder. We found that any of the 4 approaches would be expected to show an overall increase in net patient revenue relative to the status quo of referring patients to other providers for addiction care. However, providers would need to maintain at least 9 patients in treatment and no-show rates of $<34 \%$. 
Table 4. Primary and Secondary Outcomes in the First Year of Buprenorphine Treatment Implementation (Year 1) and in Each Subsequent Year (After Year 1 for Each of 10 Years) Across 4 Approaches for Office-Based Opioid Treatment With Buprenorphine, and Among the Different Simulated Practice Types

\section{Gross Revenue $\$(95 \% \mathrm{Cl})$}

\section{Opportunity Costs} $\$(95 \% \mathrm{Cl})$
New Personnel and

Overhead Costs $\$(95 \% \mathrm{Cl})$
Net Revenue
$\$(95 \% \mathrm{CI})$

Year 1

FQHC

$\begin{array}{ll}\text { Physician-led } & 41,769(17,408-73,092) \\ \text { Nurse-led } & 35,857(15,013-63,183) \\ \text { Shared } & 41,942(17,390-73,618) \\ \text { Solo } & 29,656(12,298-52,300)\end{array}$

$6,395(2,517-12,393)$
$3,240(1,438-5,964)$
$4,081(1,716-7,573)$
$7,880(3,374-14,569)$

$7,508(3,471-13,481)$

$3,996(2,014-6,793)$

$4,931(2,429-8,497)$

$9,552(4,779-16,355)$

10,027 (4,086-19,218)

$5,041(2,317-9,133)$

$6,368(2,838-11,789)$

$12,299(5,549-22,553)$

$5,976(2,115-12,076)$

$3,399(1,506-6,194)$

$4,078(1,696-7,662)$

$7,944(3,303-14,887)$

$5,519(1,779-11,327)$

2,357 (749-4,925)

3,204 (1,024-6,509)

$6,119(1,979-12,547)$

$6,153(2,333-12,012)$

2,631 (977-5,113)

$3,575(1,358-6,884)$

$6,829(2,576-13,015)$

$8,716(2,901-17,783)$

$3,721(1,228-7,608)$

$5,058(1,703-10,353)$

$9,664(3,263-19,592)$

$4,512(1,107-7,623)$
$1,923(371-4,339)$
$2,615(503-5,939)$
$5,000(983-11,455)$

$6,514(3,508-10,647)$

$9,746(4,929-16,344)$

$9,193(4,700-15,475)$

0

$6,364(3,632-9,832)$

$8,974(5,062-14,234)$

$8,521(4,810-13,509)$

$5,642(2,966-9,378)$

$8,575(4,285-14,885)$

$8,092(4,091-14,110)$

0

$6,302(3,338-10,049)$

8,296 (4,168-14,212)

7,929 (3,949-13,301)

0

$3,234(1,159-6,404)$

$6,455(2,345-12,448)$

$5,903(2,108-11,579)$

0

$2,660(1,145-5,016)$

$5,257(2,237-9,696)$

$4,806(2,053-8,917)$

0

$3,671(1,337-7,339)$

$5,786(2,116-11,413)$

$5,305(1,945-10,692)$

$$
0
$$

$2,080(427-4,650)$

$4,058(860-9,042)$

$3,695(813-8,171)$
$28,859(9,247-54,294)$

$22,870(6,258-45,087)$

$28,668(9,026-55,032)$

$21,776(7,964-40,045)$

45,769 (17,812-85,568)

$41,606(15,280-79,472)$

$45,593(17,826-85,198)$

$25,560(10,299-47,435)$

69,366 (24,814-134,442)

$64,323(22,021-126,578)$

$69,682(24,761-134,089)$

$37,596(13,617-73,853)$

$33,399(2,990-79,070)$

$30,499(2,065-75,037)$

$33,108(2,651-79,258)$

$18,141(1,702-42,051)$

$33,016(13,567-58,589)$ $27,044(10,820-49,205)$ $32,835(13,388-59,298)$

$23,538(9,683-41,899)$

$50,828(22,860-90,418)$ $46,688(20,264-84,319)$ $50,664(23,090-90,283)$ $28,283(12,938-50,689)$

72,649 (28,513-137,390) $68,432(26,186-130,898)$ $73,779(29,224-138,600)$ $40,231(16,037-76,726)$

$39,085(8,650-85,210)$

$36,212(7,785-80,774)$

$38,806(8,649-84,639)$

$21,086(4,697-45,406)$

$\mathrm{FQHC}=$ federally qualified health center

Note: The 4 approaches were (1) buprenorphine therapy via prescriber-led visits, which involved prescribers leading routine visits for medication management with a nurse care manager providing program coordination, intake visits, telephone outreach, and induction management, (2) buprenorphine therapy via nurse-led visits, which involved a nurse care manager leading patient visits and care management and prescribers meeting the patient every 3 months after induction for medication management, (3) buprenorphine therapy via shared medical appointments, which involved the prescribers leading a weekly group visit (including medication titration) in concert with a behaviorist and nurse care manager, and (4) buprenorphine therapy via a solo prescriber, which involved the physician prescribing buprenorphine without major structural support from auxiliary staff. The 4 practice types were (1) FQHCs and FQHC look-alikes, (2) non-FQHC practices in high-poverty urban areas by Census definition ( $\geq 20 \%$ of households within the ZIP Code having an income below the federal poverty threshold after adjustment for household size), (3) nonFQHC practices in high-poverty rural areas by Census definition ( $\geq 20 \%$ of households within the ZIP Code having an income below the federal poverty threshold after adjustment for household size), and (4) practices outside of high-poverty areas. 
Our results suggest that in the current fee-for-servicedominated environment, offering office-based therapy for opioid addiction with buprenorphine can be a financially attractive choice for cash-strapped primary care practices, despite hurdles including additional training requirements, applying for a waiver, and potentially hiring and training new staff. We found that approaches using nurse care management improved efficiency and led to greater net revenues, despite the up-front personnel and overhead costs, in part due to payments for nurse-led and group-based visits and because providers would not have to sacrifice as many routine in-person medical visits to support buprenorphine visits. Our results appeared to be robust across a representative range of no-show rates because no interviewed practice representative in our sample reported an initial visit noshow rate of $>25 \%$, and follow-up visit no-show rates tend to be markedly lower than this because patients generally cannot receive prescriptions without attendance. Net revenues estimated by our model were negative, however, when local prevalence of opioid use disorder decreased to $<0.3 \%$ to $0.8 \%$ across approaches and geographies or when equivalently fewer than 9 patients were taking buprenorphine at any one time. Some practices might find attracting 9 patients to be difficult, particularly during the first year of program operation.

The present study has inherent limitations. First, we did not conduct a national survey of all practices prescribing buprenorphine but rather a subset of practices available to detail their buprenorphine prescribing strategy. Thus, other practices might have found strategies not incorporated into our model. Second, whereas we clustered practices into 4 broad types to reflect the major variations among practices in costs, revenues, and patient demographics, there are inevitably within-group variations that we sought to address via uncertainty analyses. We found that to a large extent, the variations in cost and revenue were often overlapping among different practice types. Third, as payment reforms and value-based payments are introduced across the country, the revenue implications of buprenorphine therapy will change. Fourth, because attracting patients to a practice can be difficult, some practices might require grant support for up-front investments in nurse care management and care process redesign. Finally, because opioid use disorder is

\section{Figure 2. Differences in long-term (after Year 1) minimum net revenue increase with variations in the no-show rate for induction and maintenance, across practice types and alternative approaches for office-based opioid treatment with buprenorphine.}

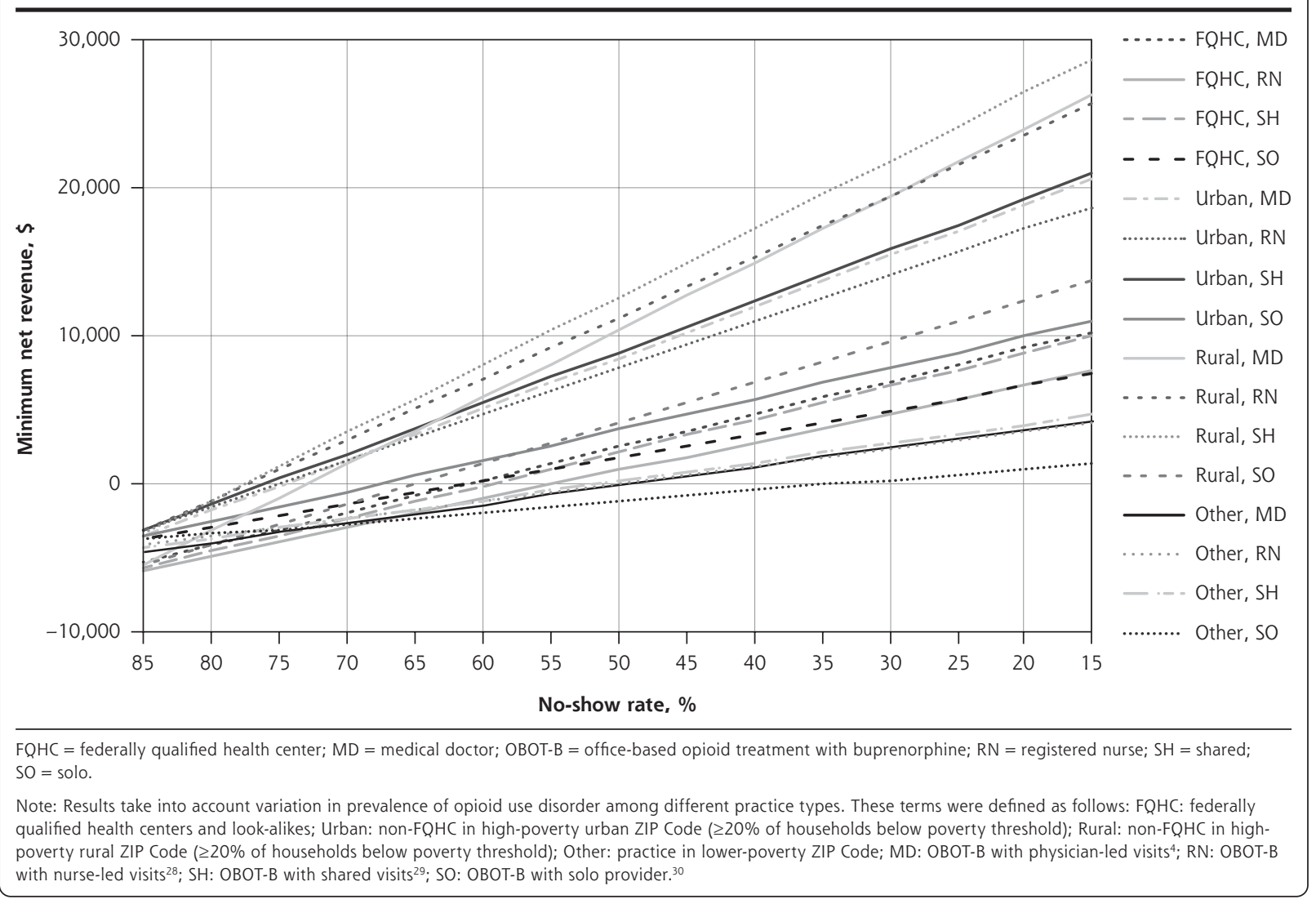




\section{Figure 3. Differences in long-term (after Year 1) minimum net revenue increase with variations in the prevalence of opioid use disorder, across practice types and alternative approaches for office-based opioid treatment with buprenorphine.}

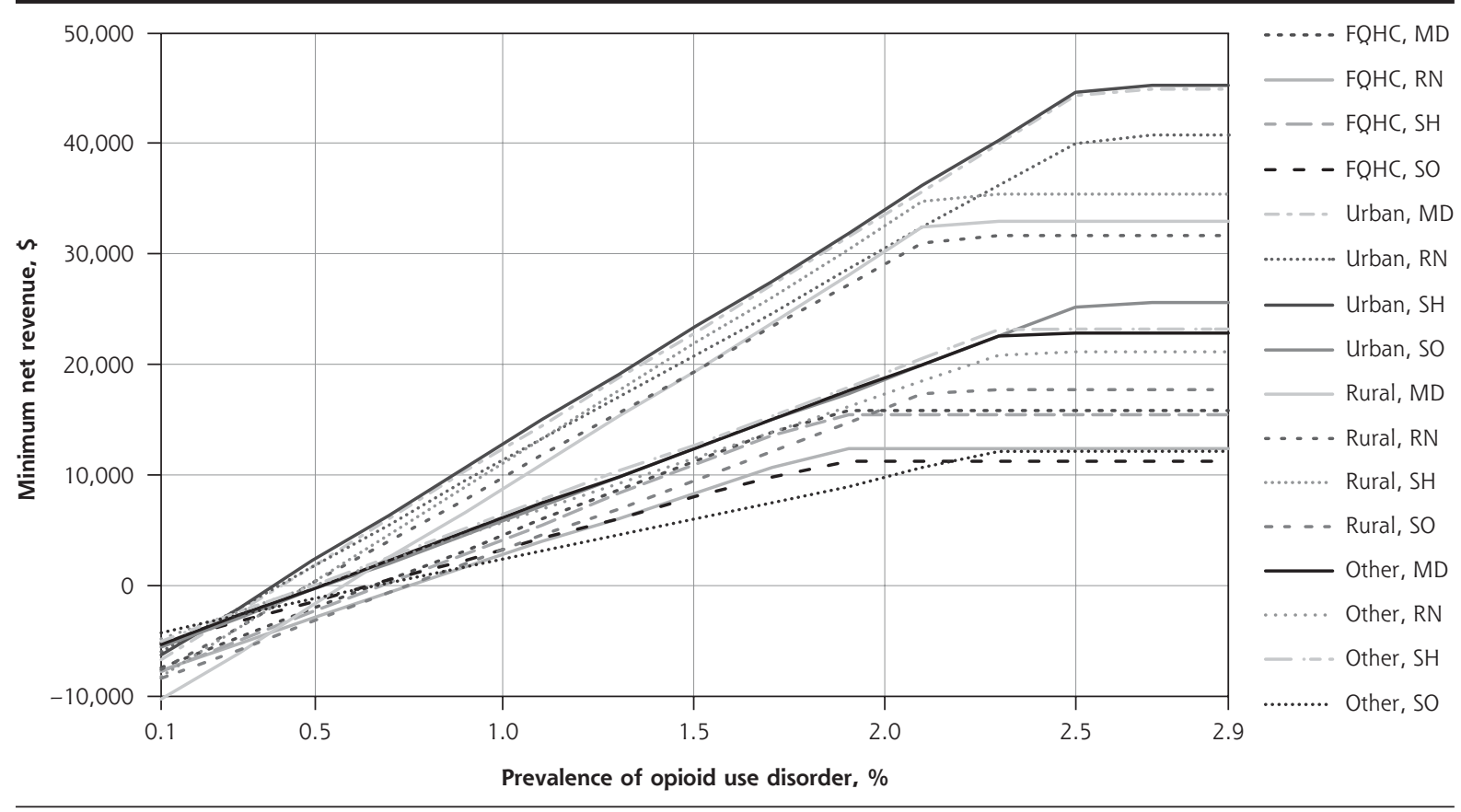

$\mathrm{FQHC}=$ federally qualified health center; $\mathrm{MD}=$ medical doctor; OBOT-B = office-based opioid treatment with buprenorphine; $\mathrm{RN}=$ registered nurse; $\mathrm{SH}=$ shared; $\mathrm{SO}=$ solo.

Note: These terms were defined as follows: FQHC: federally qualified health centers and look-alikes; Urban: non-FQHC in high-poverty urban ZIP Code ( $\geq 20 \%$ of households below poverty threshold); Rural: non-FQHC in high-poverty rural ZIP Code ( $\geq 20 \%$ of households below poverty threshold); Other: practice in lower-poverty ZIP Code; MD: OBOT-B with physician-led visits ${ }^{4}$; RN: OBOT-B with nurse-led visits ${ }^{28}$; SH: OBOT-B with shared visits ${ }^{29}$; SO: OBOT-B with solo provider. ${ }^{30}$

a dynamic epidemic, our estimates of demand might either under- or overestimate future prescribing rates.

In the future, financial modeling studies should consider the effect of bundling opioid use disorder treatments, spanning the divide between primary care and psychiatry. In addition, the effect of lifting the 30-patients-per-provider limit deserves further attention.

Overall, the results of the present study imply that primary care practices adopting any of 4 common approaches to buprenorphine-based treatment of opioid use disorder would be expected to observe an overall increase in net patient revenue, particularly when adopting a nurse care manager-based approach and when maintaining a critical level of demand and low no-show rates.

To read or post commentaries in response to this article, see it online at https://www.AnnFamMed.org/content/18/6/535.

Key words: primary care; opioid use disorder; health care financing; buprenorphine

Submitted January 7, 2020; submitted, revised, March 19, 2020; accepted June 3, 2020.

Supplemental materials: Available at https://www.AnnFamMed. org/content/18/6/535/suppl/DC1/.

\section{References}

1. Mattick RP, Breen C, Kimber J, Davoli M. Buprenorphine maintenance versus placebo or methadone maintenance for opioid dependence. Cochrane Database Syst Rev. 2014;2:CD002207.

2. Sordo L, Barrio G, Bravo MJ, et al. Mortality risk during and after opioid substitution treatment: systematic review and meta-analysis of cohort studies. BMJ. 2017;357:j1550.

3. Substance Abuse and Mental Health Services Administration. Medications for Opioid Use Disorder. US Department of Health and Human Services; 2018.

4. Fiellin DA, Moore BA, Sullivan LE, et al. Long-term treatment with buprenorphine/naloxone in primary care: results at 2-5 years. Am J Addict. 2008;17(2):116-120.

5. Alford DP, LaBelle CT, Kretsch N, et al. Collaborative care of opioidaddicted patients in primary care using buprenorphine: five-year experience. Arch Intern Med. 2011;171(5):425-431.

6. Wakeman SE, Rigotti NA, Chang Y, et al. Effect of integrating substance use disorder treatment into primary care on inpatient and emergency department utilization. J Gen Intern Med. 2019;34(6): 871-877.

7. Cole ES, DiDomenico E, Cochran G, et al. The role of primary care in improving access to medication-assisted treatment for rural Medicaid enrollees with opioid use disorder. J Gen Intern Med. 2019; 34(6):936-943.

8. Barry CL, Epstein AJ, Fiellin DA, Fraenkel L, Busch SH. Estimating demand for primary care-based treatment for substance and alcohol use disorders. Addiction. 2016;111(8):1376-1384. 
9. O'Connor PG, Oliveto AH, Shi JM, et al. A randomized trial of buprenorphine maintenance for heroin dependence in a primary care clinic for substance users versus a methadone clinic. Am J Med. 1998;105(2):100-105.

10. Bell JR, Butler B, Lawrance A, Batey R, Salmelainen P. Comparing overdose mortality associated with methadone and buprenorphine treatment. Drug Alcohol Depend. 2009;104(1-2):73-77.

11. Marteau D, McDonald R, Patel K. The relative risk of fatal poisoning by methadone or buprenorphine within the wider population of England and Wales. BMJ Open. 2015;5(5):e007629.

12. Beetham T, Saloner B, Wakeman SE, Gaye M, Barnett ML. Access to office-based buprenorphine treatment in areas with high rates of opioid-related mortality: an audit study. Ann Intern Med. 2019; 171(1):1-9.

13. Sigmon SC. The untapped potential of office-based buprenorphine treatment. JAMA Psychiatry. 2015;72(4):395-396.

14. Rosenblatt RA, Andrilla CH, Catlin M, Larson EH. Geographic and specialty distribution of US physicians trained to treat opioid use disorder. Ann Fam Med. 2015;13(1):23-26.

15. Wen $H$, Borders TF, Cummings JR. Trends in buprenorphine prescribing by physician specialty. Health Aff (Millwood). 2019;38(1): 24-28.

16. Truven Health Analytics. Use of Medication-Assisted Treatment for Opioid Use Disorders in Employer-Sponsored Health Insurance: Final Report. US Department of Health and Human Services, Office of Disability, Aging, and Long-Term Care Policy; 2019.

17. Walley AY, Alperen JK, Cheng DM, et al. Office-based management of opioid dependence with buprenorphine: clinical practices and barriers. J Gen Intern Med. 2008;23(9):1393-1398.

18. Haffajee RL, Bohnert ASB, Lagisetty PA. Policy pathways to address provider workforce barriers to buprenorphine treatment. Am J Prev Med. 2018;54(6 Suppl 3):S230-S242.

19. Andrilla CHA, Coulthard C, Larson EH. Barriers rural physicians face prescribing buprenorphine for opioid use disorder. Ann Fam Med. 2017;15(4):359-362.

20. Storholm ED, Ober AJ, Hunter SB, et al. Barriers to integrating the continuum of care for opioid and alcohol use disorders in primary care: a qualitative longitudinal study. J Subst Abuse Treat. 2017;83:45-54.

21. Hutchinson E, Catlin M, Andrilla CH, Baldwin LM, Rosenblatt RA. Barriers to primary care physicians prescribing buprenorphine. Ann Fam Med. 2014;12(2):128-133.

22. Knudsen HK, Abraham AJ, Oser CB. Barriers to the implementation of medication-assisted treatment for substance use disorders: the importance of funding policies and medical infrastructure. Eval Program Plann. 2011;34(4):375-381.

23. Huhn AS, Dunn KE. Why aren't physicians prescribing more buprenorphine? J Subst Abuse Treat. 2017;78:1-7.

24. Netherland J, Botsko M, Egan JE, et al. Factors affecting willingness to provide buprenorphine treatment. J Subst Abuse Treat. 2009; 36(3):244-251.

25. Schackman BR, Leff JA, Polsky D, Moore BA, Fiellin DA. Cost-effectiveness of long-term outpatient buprenorphine-naloxone treatment for opioid dependence in primary care. J Gen Intern Med. 2012; 27(6):669-676.

26. Jones ES, Moore BA, Sindelar JL, O'Connor PG, Schottenfeld RS, Fiellin DA. Cost analysis of clinic and office-based treatment of opioid dependence: results with methadone and buprenorphine in clinically stable patients. Drug Alcohol Depend. 2009;99(1-3):132-140.

27. Murphy SM, McCollister KE, Leff JA, et al. Cost-effectiveness of buprenorphine-naloxone versus extended-release naltrexone to prevent opioid relapse. Ann Intern Med. 2019;170(2):90-98.

28. Husereau D, Drummond M, Petrou S, et al; ISPOR Health Economic Evaluation Publication Guidelines-CHEERS Good Reporting Practices Task Force. Consolidated Health Economic Evaluation Reporting Standards (CHEERS)--explanation and elaboration: a report of the ISPOR Health Economic Evaluation Publication Guidelines Good Reporting Practices Task Force. Value Health. 2013;16(2):231-250.
29. Korthuis PT, McCarty D, Weimer M, et al. Primary care-based models for the treatment of opioid use disorder. Ann Intern Med. 2016; 166(4):268-278.

30. Lagisetty P, Klasa K, Bush C, Heisler M, Chopra V, Bohnert A. Primary care models for treating opioid use disorders: what actually works? A systematic review. PLoS One. 2017;12(10):e0186315.

31. Glaser BG, Strauss AL. The Discovery of Grounded Theory: Strategies for Qualitative Research. Aldine Publishing Company; 1967.

32. Lacey A, Luff D; National Institute for Health Research, The NIHR Research Design Service for the East Midlands/Yorkshire $\&$ the Humber. Qualitative data analysis. Published 2007. Accessed Sep 29, 2020. https://www.rds-yh.nihr.ac.uk/wp-content/uploads/2013/ 05/9_Qualitative_Data_Analysis_Revision_2009.pdf.

33. Basu S, Landon BE, Song Z, Bitton A, Phillips RS. Implications of workforce and financing changes for primary care practice utilization, revenue, and cost: a generalizable mathematical model for practice management. Med Care. 2015;53(2):125-132.

34. Centers for Medicare \& Medicaid Services, Medicaid Innovation Accelerator Program. Clinical pathways for patients in substance use disorder treatment including the use of buprenorphine, model \#2: Massachusetts primary care practices/clinics. Published Jan 5, 2017. Accessed Oct 30, 2020. https://www.medicaid.gov/state-resourcecenter/innovation-accelerator-program/iap-downloads/reducingsubstance-use-disorders/mat-clinical-pathway-model-2.pdf.

35. Sokol R, Albanese $M$, Albanese $C$, et al. Implementing group visits for opioid use disorder: a case series. Subst Abus. 2020;41(2): 174-180.

36. Mintzer IL, Eisenberg M, Terra M, MacVane C, Himmelstein DU, Woolhandler S. Treating opioid addiction with buprenorphinenaloxone in community-based primary care settings. Ann Fam Med. 2007;5(2):146-150.

37. US Office of Personnel Management. Fact sheet: computing hourly rates of pay using the 2,087-hour divisor. Accessed Nov 20, 2019. https://www.opm.gov/policy-data-oversight/pay-leave/payadministration/fact-sheets/computing-hourly-rates-of-pay-usingthe-2087-hour-divisor/.

38. US Department of Health and Human Services. Substance Abuse and Mental Health Services Administration, Substance Abuse $\&$ Mental Health Data Archive. National Survey on Drug Use and Health, 2017 (NSDUH-2017-DS0001). Accessed Sep 29, 2020. https://datafiles.samhsa.gov/study-dataset/national-survey-drug-useand-health-2017-nsduh-2017-ds0001-nid17939.

39. Smith PC, Schmidt SM, Allensworth-Davies D, Saitz R. A singlequestion screening test for drug use in primary care. Arch Intern Med. 2010;170(13):1155-1160.

40. Medical Group Management Association. DataDive. 2019. Accessed Oct 30, 2020. https://www.mgma.com/data/landing-pages/mgmadatadive-overview.

41. US Bureau of Labor Statistics. Occupational outlook handbook. Published Sep 4, 2019. Accessed Oct 30, 2019. https://www.bls.gov/ooh/.

42. Centers for Medicare \& Medicaid Services. Medicare physician fee schedule search. Published Oct 4, 2019. Accessed Oct 30, 2019. https://www.cms.gov/apps/physician-fee-schedule/search/searchcriteria.aspx.

43. Zuckerman S, Skopec L, Epstein M; Urban Institute. Medicaid physician fees after the ACA primary care fee bump. Published Mar 9, 2017. Accessed Oct 30, 2019. https://www.urban.org/research/ publication/medicaid-physician-fees-after-aca-primary-care-fee-bump.

44. Collective Health. Collective insights. Accessed Nov 4, 2019. https:// collectivehealth.com/insights/.

45. US Department of Health and Human Services. Substance Abuse and Mental Health Services Administration. Practitioner and program data. Published Sep 16, 2019. Accessed Oct 30, 2020. https://www.samhsa.gov/medication-assisted-treatment/ practitioner-program-data/certified-practitioners. 